\title{
Meet the flow chemist - Prof. Norbert Kockmann
}

\section{Timothy Noël ${ }^{1}$}

Published online: 6 September 2021

(c) Akadémiai Kiadó 2021

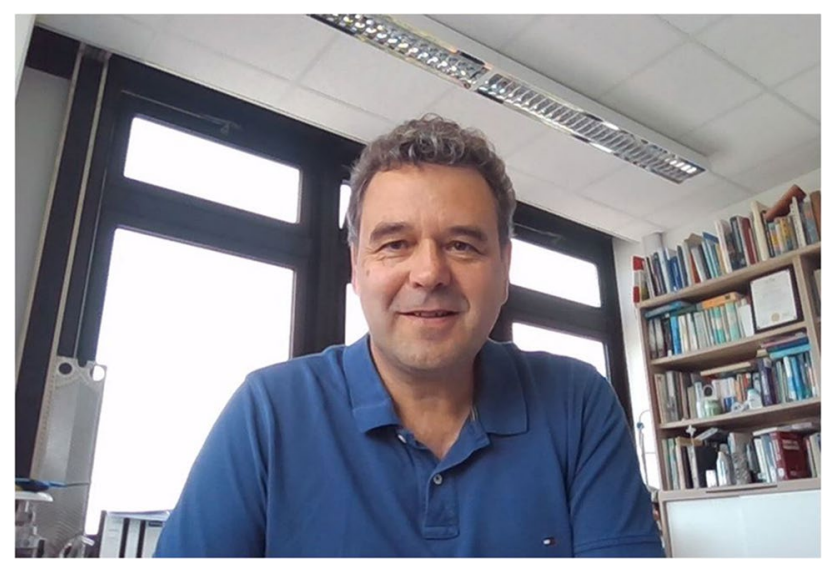

\begin{tabular}{|c|c|}
\hline Name & Norbert Kockmann \\
\hline Date of Birth & July 4, 1966 \\
\hline Position & $\begin{array}{l}\text { since } 2011 \text { Professor of Equipment Design \& Dean } \\
\text { of Studies in the faculty of Biochemical and } \\
\text { Chemical Engineering, TU Dortmund University }\end{array}$ \\
\hline E-mail & norbert.kockmann@tu-dortmund.de \\
\hline Homepage & ad.bci.tu-dortmund.de \\
\hline Education & $\begin{array}{l}\text { 1985-91 Diploma in Mechanical Engineering, TU } \\
\text { Munich; } 1996 \text { Dr.-Ing. in Production Engineer- } \\
\text { ing at Bremen University; } 2007 \text { Habilitation in } \\
\text { Microsystems Engineering at Freiburg University }\end{array}$ \\
\hline Past Positions & $\begin{array}{l}\text { 1997-2001 Project manager at Messer Griesheim, } \\
\text { Krefeld, for large process plants; 2007-2011 Head } \\
\text { of chemical laboratory and Senior Scientist at } \\
\text { Lonza, Visp }\end{array}$ \\
\hline Awards & $\begin{array}{l}2009 \text { ASME ICNMM09 Outstanding Researcher } \\
\text { Award } 2010 \text { Sandmeyer Prize for Industrial } \\
\text { Chemistry of Swiss Chemical Society } 2015 \text { ASME } \\
\text { ICNMM2015 Outstanding Researcher Award } 2018 \\
\text { CIT-Lecture on ProcessNet Annual Meeting Several } \\
\text { best presentation and best poster awards }\end{array}$ \\
\hline
\end{tabular}

During my $\mathrm{PhD}$ period, I already tried to minimize process equipment for simpler setup and operation. I was fascinated by a millimeter-size freezing unit of my colleague investigating the diffusion behavior of salt solutions. Although large chemical production plants have their attraction, small equipment is often better controllable and more efficient in heat and mass transfer. I got the opportunity to start my second attempt in academic career at the Microsystems Engineering Institute in Freiburg, Germany, to investigate microreactors and processes therein. One of the first papers out of a master thesis of Thomas Kiefer dealt with the mixing phenomena in T-shaped micromixers. It took long time to convince the reviewers that vortices appear already at low Reynolds numbers and hence

Timothy Noël

t.noel@uva.nl

1 Department of Chemical Engineering and Chemistry, Eindhoven University of Technology, Eindhoven, Netherlands microchannel flow is not governed by laminar convection and diffusive mass transfer alone. We dig deeper into microchannel mixing and (re-)found the beneficial role of secondary flow for mixing and heat transfer, which is nowadays completely accepted in science and a lively research area. The Coiled Flow Inverter was characterized in similar way as the T-mixer and can serve together with improved contacting devices for successful flow chemistry with defined scale-up rules.

2) What are the main benefits of flow that convinced you to use and implement this technology in your research?

We started with the motivation of controllable reaction conditions from mixing and heat transfer leading to less footprint in size and operation, optimal reaction conditions. With automated operation you get a lot of information in short time, leading to high throughput screening, now already assisted by inline analytics. You achieve more information with less 
effort. During my industrial time, we were convinced to perform reactions impossible in batch mode and could show this several times. The bottleneck often shifts to work-up steps, hence, my academic activities focused then on separation steps and solids handling. We have developed columns for solvent extraction and distillation with superior performance and well-known scaleup conditions together with a toolbox for continuous crystallization. This will lead to improved sustainability in chemical process development and production.

\section{3) What do you think the future holds for flow chemistry?}

With improved automation and adapted inline sensors for process control, we can change the fine chemicals and pharmaceutical production from batch to continuous mode for sustainable manufacturing of environmentally benign products. We have to start in higher education to train chemists and engineers on the modern tools. For future chemical production, decentralized production on demand with reconfigurable plants consisting of modular, small-scale equipment will lead to many new applications of flow chemistry.

\section{4) Do you have any relevant tips for newcomers in the field?}

Start simple with capillary setup, take care of pumps and analytics, and calculated with proper mass and component balances. From my experience, personal frustration tolerance is very important, since not all runs properly on the first try. A step-by-step approach is very helpful and gives time to discover the silver stripe at the horizon. A prepared mind is helpful for serendipity.

\section{My three most relevant papers related to flow chemistry.}

1) N. Kockmann, D.M. Roberge, Harsh Reaction Conditions in Continuous-Flow Microreactors for Pharmaceutical Production, Chem. Eng. \& Technol. 32, No. 11, 1682-1694, 2009, https://doi.org/10.1002/ceat.200900355
The contribution is a summary of most of my convective mixing studies as well as heat transfer and the applications of exothermic reactions in microreactors. Major design criteria are given, comprehensive for beginners, too. Simple chemical examples from industrial applications are presented with scale-up considerations.

2) L. Hohmann, S.K. Kurt, S. Soboll, N. Kockmann, Separation Units and Equipment for Lab-Scale Process Development, J. Flow Chem., 6(3) 181-190, 2016; https://doi.org/10. $1556 / 1846.2016 .00024$

This publication discusses the reactor geometry of the Coiled Flow Inverter CFI for particle generation and growth during crystallization together with solvent extraction and two-phase separation. It gives a nice overview on possible thermal and mechanical separation steps on small scale in the laboratory. However, distillation and further automation are still missing here, which is already feasible, but many basics are well explained.

3) N. Kockmann, Digital methods and tools for chemical equipment and plants, Reac. Chem. \& Eng., 4, 1522-1529, 2019, https://doi.org/10.1039/C9RE00017H

This perspective on digital tools in process technology shows many opportunities and benefits of digitalization for flow chemistry, too, which will become more and more important. Available sensors and related analytics, automation and AI tools as well as high throughput experimentation will give new thrust for flow chemistry and its applications. Additionally, education and work flows in laboratory and process development must be adapted to the new tools.

Publisher's Note Springer Nature remains neutral with regard to jurisdictional claims in published maps and institutional affiliations. 